\title{
Forehead reconstruction with a custom-made three- dimensional titanium implant in a Parry-Romberg syndrome patient
}

Jae Yoon Kim,

Bok Ki Jung,

Young Suk Kim,

Tai Suk Roh,

In Sik Yun

Department of Plastic and Reconstructive Surgery, Institute for Human Tissue

Restoration, Gangnam Severance Hospital, Yonsei University College of Medicine, Seoul, Korea
Parry-Romberg syndrome is a rare neurocutaneous syndrome characterized by progressive shrinkage and degeneration of the tissues usually on only one side of the face. It is usually difficult to restore the facial contour due to skin tightness. In this case report, we report a forehead reconstruction with custom-made three-dimensional (3D) titanium implant of a Parry-Romberg syndrome patient who was treated with multiple fat grafts but had limited effect. A 36-year-old man presented with hemifacial atrophy. The disease progressed from 5 to 16 years old. The patient had alopecia on frontal scalp and received a surgery using tissue expander. The alopecia lesion was covered by expanded scalp flap done 22 years ago. Also, he was treated with fat grafts on depressed forehead 17 years ago. However, it did not work sufficiently, and there was noted depressed forehead. We planned to make 3D titanium implant to cover the depressed area (from the superior orbital rim to the vertex). During the operation, we confirmed that the custom-made 3D implant accurately fit for the depressed area without any dead spaces. Previously depressed forehead and glabella were elevated, and the forehead contour was improved cosmetically. A custom-made 3D titanium implant is widely used for skull reconstruction and bring good results. In our case, the depressed forehead of a Parry-Romberg syndrome patient was improved by a 3D titanium implant.

Keywords: Titanium / Facial hemiatrophy / Parry-Romberg disease

\section{INTRODUCTION}

Parry-Romberg syndrome (also known as progressive hemifacial atrophy) is a rare neurocutaneous syndrome characterized by progressive shrinkage and degeneration of the tissues usually on only one side of the face [1].

It is a rare, acquired, neurocutaneous syndrome of unknown etiology accounting one in 700,000 individuals [2]. This condition was first reported by an English physician, Caleb Parry, in 1815, and subsequently elaborated in 1846 by Moritz Romberg [2]. The

\footnotetext{
Correspondence: In Sik Yun
}

Department of Plastic and Reconstructive Surgery, Yonsei University College of Medicine, 50 Yonsei-ro, Seodaemun-gu, Seoul 03722, Korea

E-mail: EQATOM@yuhs.ac

Received December 18, 2017 / Revised April 24, 2018 / Accepted April 27, 2018 principal goal of plastic surgery is to restore a harmonious and symmetrical appearance through soft tissue restoration and bone framework reconstruction [3]. Many procedures that focus on soft tissue reconstruction have been reported, including autologous fat graft, dermal graft, microvascular free flaps such as scapular and parascapular flaps [4,5], anterolateral thigh flap [6,7], and omentum free flap $[8,9]$, but the results are often unsatisfactory for certain severe cases owing to the involvement of the underlying bony framework. In this case report, we report a forehead reconstruction with custom-made three-dimensional (3D) titanium implant of a Parry-Romberg syndrome patient treated with multiple fat grafts but had limited effect. 


\section{CASE REPORT}

A 36-year-old man presented with hemifacial atrophy (depressed forehead and glabella area). The disease progressed from 5 to 16 years old. The patient had alopecia on frontal scalp and received a surgery using tissue expander. The alopecia lesion was covered by expanded scalp flap done 22 years ago. Also, he was treated with fat grafts on depressed forehead 17 years ago. However, it did not work sufficiently, and there was noted depressed forehead (Figs. 1, 2). We planned to make 3D titanium implant to cover the depressed area (from the superior orbital rim to the vertex) (Fig. 3).

The titanium implant was manufactured and fabricated by Medyssey (Dongducheon, Korea) using 3D computed tomography data and an electron beam melting machine. We used Mim-
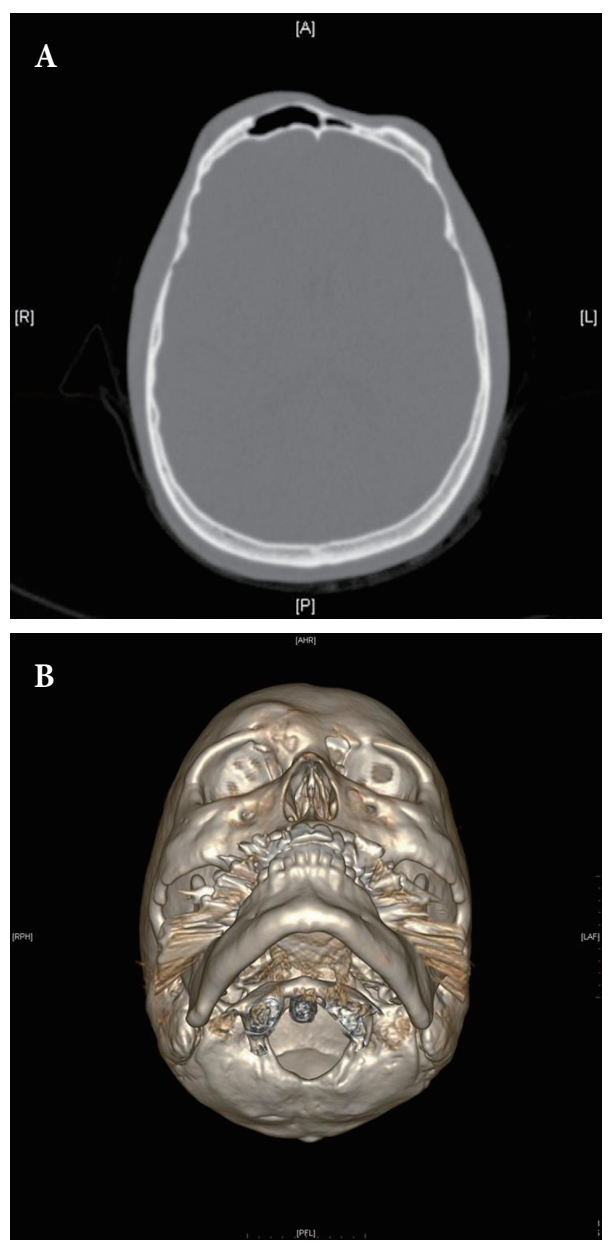

Fig. 1. Preoperative computed tomography facial bone axial (A) and three-dimensional (B) views.
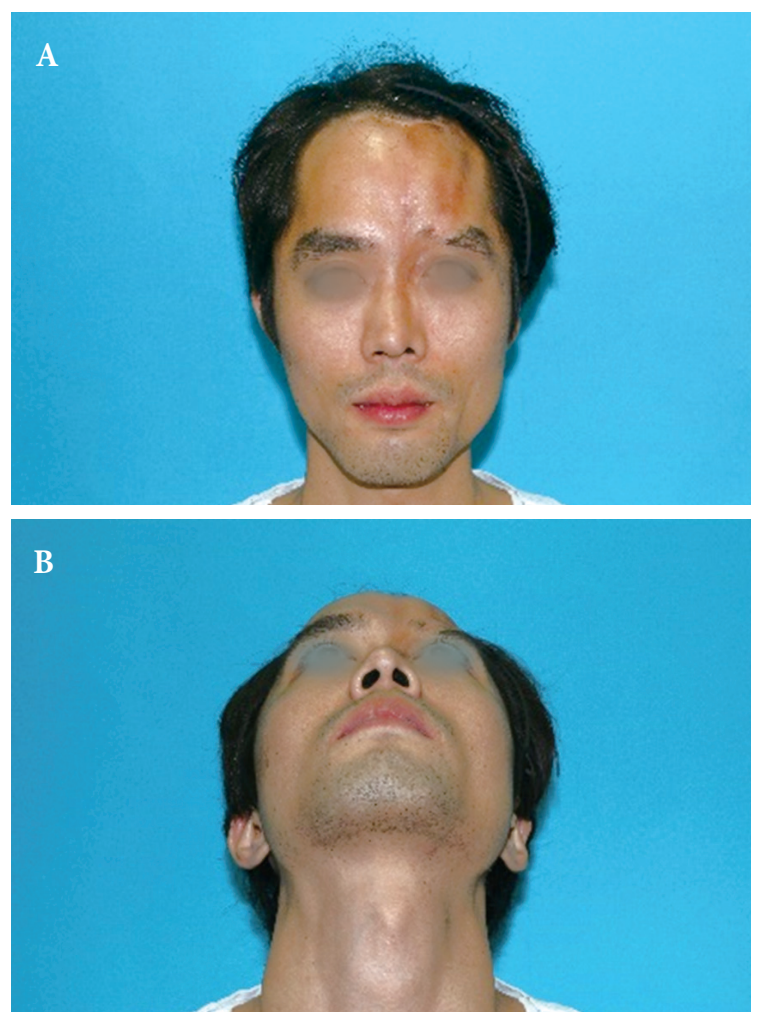

Fig. 2. Preoperative views of a 36-year-old man with Parry-Romberg syndrome. (A) Front view. (B) Worm's eye view.

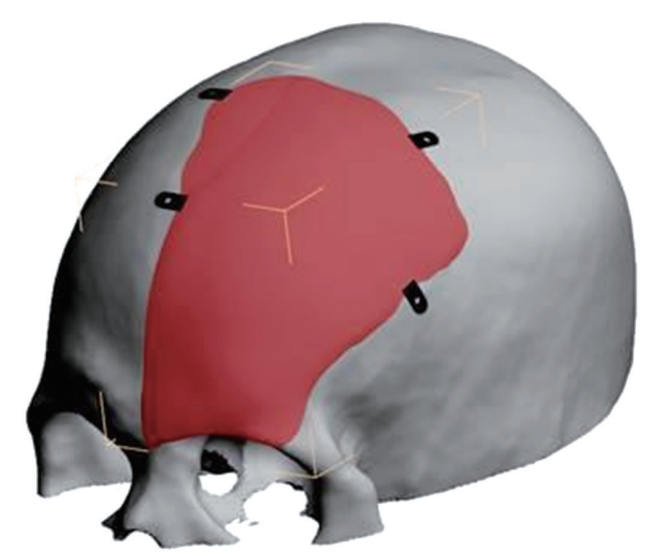

Fig. 3. Preoperative three-dimensional computed tomography and target area.

ics software for 3D printing. The final implant design incorporated 2-mm thickness for bone-like rigidity. After manufacturing the 3D implant, we simulated the operation with it to the patient's rapid prototyping model. Under general endotracheal anesthesia, we made bicoronal incision using previous scar, and exposed the 
whole depressed area, and fixed the 3D titanium implant with 4-mm titanium screws. During the operation, we confirmed that the custom-made 3D implant accurately fit for the depressed area without any dead spaces (Fig. 4). A negative drain was inserted under the scalp, and total operation time was 2 hours 30 minutes. The operative site healed without any complication. Previously depressed forehead and glabella lesions were elevated, and the forehead contour was improved cosmetically. No complications were reported. The patient was seen 1 month after the intervention. He was satisfied with the result obtained. The patient returned to our clinic 6 months after the intervention in order to evaluate the result. He stated that he no longer had a depressed forehead (Fig. 5).

\section{DISCUSSION}

For Parry-Romberg syndrome patients, making symmetry and restoration of contour are the main challenge. There are several different reconstructive methods with augmentation of deficient soft-tissue volume such as fat grafts, dermis fat grafts, pedicle flaps, bone grafts, microvascular free flaps, and alloplastic implants [10].

There has been recently proposed four-types classification for the treatment of facial tissue atrophy in Parry-Romberg disease for types 1 and 2 which involve only the soft facial tissue, fat grafts are used, whereas for types 3 and 4 in which alteration of soft and

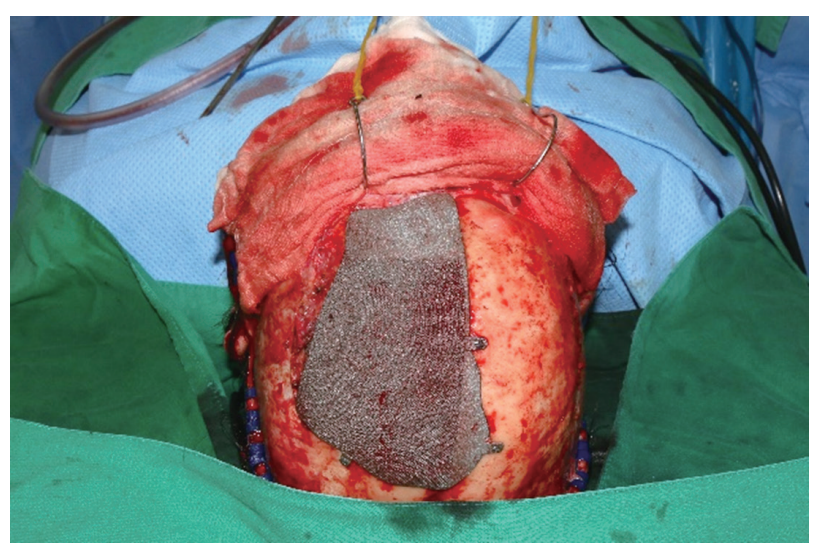

Fig. 4. Custom-made three-dimensional titanium implant accurately fit for the depressed area without any dead spaces, fixed with 4-mm screws.
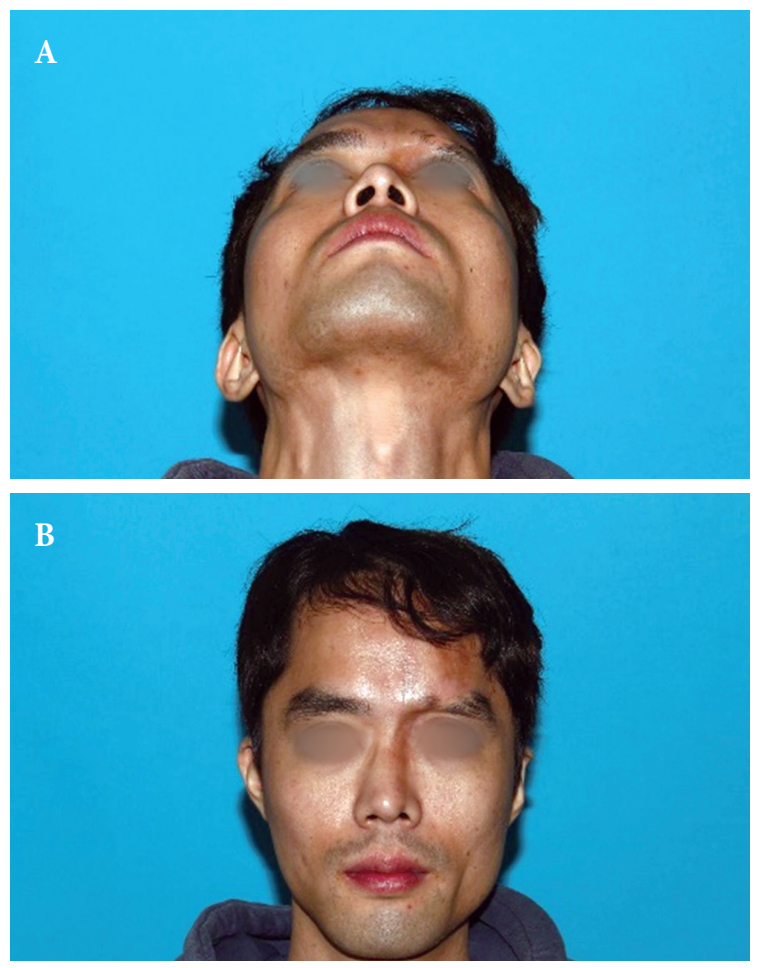

Fig. 5. Postoperative views 6 months after the intervention. (A) Front view. (B) Worm's eye view.

bony tissue occurs, a combined procedure using cartilage and bone grafts, free dermis-fat grafts, and galeal flaps is proposed [11]. A custom-made 3D titanium implant was also a good alternative for the treatment of Parry-Romberg syndrome patients, especially types 3 and 4 .

An ideal material for skull implant should be durable, strong, lightweight, nonferromagnetic, and noncarcinogenic. Many materials have been used such as polymethylmethacrylate, hydroxyapatite, porous polyethylene implant (MEDPOR; Stryker, Kalamazoo, MI, USA) and titanium implant. All of them have proven to be biocompatible but have individual shortcomings. Compared to titanium, polymethylmethacrylate and hydroxyapatite are associated with an increased risk of infection. Polyethylene is not as strong as titanium [12-14]. Titanium is enough resistant to secondary trauma while providing maximal stability of the cranial vault. Furthermore, titanium implants generally cause less inflammation and conducts well with surrounding mineralized bone [15].

With development in 3D printing processes, titanium implants 
could be fabricated using electron beams to shape titanium structure [16]. In our experience, the implant fit the target area precisely. There were several limitations of this study. One of them is lack of small number and long-term follow-up data. We followed him only for 6 months because of the patient's condition. We could not identify the appearance of the patient after 6 months.

Also, the soft tissue of forehead was contracted because of the characteristic of Parry-Romberg syndrome disease, therefore, it was very hard to make perfect symmetry of forehead. The titanium implant used in this case is made of a uniform thickness of 2 $\mathrm{mm}$. If the thickness is made differently depending on the extent of the depressed area, it can reduce dead space followed by reducing seroma and risk of infection. Further studies in the future involving implant thickness depending on the depressed area are needed. In conclusion, the depressed forehead of a Parry-Romberg syndrome patient was augmented substantially by a 3D titanium implant.

\section{CONFLICT OF INTEREST}

No potential conflict of interest relevant to this article was reported.

\section{PATIENT CONSENT}

The patients provided written informed consent for the publication and the use of their images.

\section{REFERENCES}

1. Sharma M, Bharatha A, Antonyshyn OM, Aviv RI, Symons SP. Case 178: Parry-Romberg syndrome. Radiology 2012;262:721-5.
2. Rangare AL, Babu SG, Thomas PS, Shetty SR. Parry-romberg syndrome: a rare case report. J Oral Maxillofac Res 2011;2:e5.

3. Hu J, Yin L, Tang X, Gui L, Zhang Z. Combined skeletal and soft tissue reconstruction for severe Parry-Romberg syndrome. J Craniofac Surg 2011;22:937-41.

4. Rigotti G, Cristofoli C, Marchi A, Bruti M, Pignatti M. Treatment of Romberg's disease with parascapular free flap and polyethylene porous implants. Facial Plast Surg 1999;15:317-25.

5. Vaienti L, Soresina M, Menozzi A. Parascapular free flap and fat grafts: combined surgical methods in morphological restoration of hemifacial progressive atrophy. Plast Reconstr Surg 2005;116:699-711.

6. Teng L, Jin X, Wu G, Zhang Z, Ji Y, Xu J, et al. Correction of hemifacial atrophy using free anterolateral thigh adipofascial flap. J Plast Reconstr Aesthet Surg 2010;63:1110-6.

7. Wang X, Qiao Q, Liu Z, Zhao R, Zhang H, Yang Y, et al. Free anterolateral thigh adipofascial flap for hemifacial atrophy. Ann Plast Surg 2005;55:617-22.

8. Asai S, Kamei Y, Nishibori K, Katoh T, Torii S. Reconstruction of Romberg disease defects by omental flap. Ann Plast Surg 2006;57:154-8.

9. Wallace JG, Schneider WJ, Brown RG, Nahai FM. Reconstruction of hemifacial atrophy with a free flap of omentum. Br J Plast Surg 1979;32:15-8

10. Suominen EA, Niemi TS, Koskivuo IO, Bruck NM, Saaristo AM. Free latissimus dorsi perforator flap for reconstruction of hemifacial atrophy: case report. Microsurgery 2007;27:369-71.

11. Guerrerosantos J, Guerrerosantos F, Orozco J. Classification and treatment of facial tissue atrophy in Parry-Romberg disease. Aesthetic Plast Surg 2007;31:424-34.

12. Ducic Y. Titanium mesh and hydroxyapatite cement cranioplasty: a report of 20 cases. J Oral Maxillofac Surg 2002;60:272-6.

13. Moreira-Gonzalez A, Jackson IT, Miyawaki T, Barakat K, DiNick V. Clinical outcome in cranioplasty: critical review in long-term followup. J Craniofac Surg 2003;14:144-53.

14. Blake GB, MacFarlane MR, Hinton JW. Titanium in reconstructive surgery of the skull and face. Br J Plast Surg 1990;43:528-35.

15. Neligan PC. Plastic surgery. London: Elsevier Saunders; 2013.

16. Winder J, Cooke RS, Gray J, Fannin T, Fegan T. Medical rapid prototyping and 3D CT in the manufacture of custom made cranial titanium plates. J Med Eng Technol 1999;23:26-8. 